1 EFFECT OF MIXING TIME AND TEMPERATURE ON

2 CRACKING RESISTANCE OF BITUMINOUS MIXTURES

3 CONTAINING RECLAIMED ASPHALT PAVEMENT MATERIAL

4 Domingo Pérez Madrigal,

5 Ph.D. candidate, Dept. of Civil and Environmental Engineering,

6 Technical University of Catalonia, 08034 Barcelona, Spain

7 Andrea Iannone,

8 Graduate Student, Dept. of Civil and Environmental Engineering,

9 Politecnico di Milano, 20133 Milan, Italy

10 Adriana Martìnez, (corresponding author)

11 Associate Professor, Dept. of Civil and Environmental Engineering

12 Technical University of Catalonia, 08034 Barcelona, Spain

13 Phone +34934017273 , Fax +34934017264

14 adriana.martinez@upc.edu

\title{
Filippo Giustozzi,
}

Assistant Professor, Dept. of Civil and Environmental Engineering, Politecnico di Milano, 20133 Milan, Italy

Phone +390223996617 , Fax +390223996602

filippo.giustozzi@polimi.it

\section{Abstract}

The use of reclaimed asphalt pavement (RAP) in bituminous mixtures is considerably increasing due to the environmental and economic benefits of recycled materials. However, stiffer mixes, usually resulting from RAP addition, have raised concern about long term properties of the pavement; a mechanical characterization of these mixes is thus needed. In this study, the effect of mixing condition on bituminous mixtures containing RAP was evaluated. Volumetric and mechanical properties were analysed. An experimental program, with the aim of measuring stiffness modulus, water sensitivity and cracking resistance, was conducted. Cracking resistance was evaluated according to the Fénix test since it has proved to be a convenient and effective method for characterizing cracking behaviour of bituminous mixtures at different temperatures.

Mixtures containing $20 \%$ or $40 \%$ of Reclaimed Asphalt Pavement (RAP) material were tested; virgin aggregates and RAP mixing temperatures as well as mixing time were varied and 
comparisons with a reference mix were conducted to characterize fracture energy and mechanical performance.

Keywords: recycling, RAP, cracking resistance, Fénix test, asphalt pavement, degree of blending

\section{Background}

In the last decades energy saving and preservation of the environment have acquired a major importance in trying to curtail climate change. In roads construction this objective is pursued with the increasing use of reclaimed asphalt pavement, also called RAP. The use of this material allows an economization of energy, new fossil material and financial resources. However, it must be also considered the need to develop a new pavement mixture without negatively impacting performance. Since bituminous mixtures containing RAP are usually stiffer, it is recommended to investigate their cracking resistance. As shown by Ozer and Al-Qadi (2009), low RAP percentages in the mix (up to 20\%) seem to have insignificant effects on the blended binders. Hence also cracking resistance remains almost unchanged. However, when a higher amount of RAP is used, the effect of the aged binder on the mix properties becomes significant.

One crucial parameter when addressing cracking resistance is the fracture energy, which is the energy required to produce a unit surface area crack. In asphalt specimens, the load initially creates an elastic strain that may trigger a fracture. If this happens the energy is then used to propagate the cracking and deform the specimen. To evaluate fracture energy, different tests are available. The semi-circular bending test or SCB test (EN 12697-44, 2011), and the disc-shaped compact tension test or DC(T) test (ASTM D7313, 2013), are the most common. From both tests, similar parameters can be obtained and both are commonly conducted during the mix-design phase to improve cracking resistance of mixes. A new test, called Fénix, was developed by the Barcelona Tech with the aim of characterising the cracking resistance of bituminous mixtures. The Fénix test is easily feasible and overcomes the disadvantages of other tests, i.e. the arch effect in the SCB and the specimen shaping in the DC(T) (Wagoner et al. 2005). Furthermore, it has been demonstrated that the Fénix configuration is more reliable at higher temperature than the SCB (Pérez-Jiménez et al. 
2013). Pérez-Jiménez et al. also obtained a correlation between the Fénix and fatigue law parameters (2011) and demonstrated that this test can give an all-around characterisation of the cracking resistance of a pavement.

At high RAP percentages, it is very difficult to know to what extent the aging of the RAP binder affects the properties of the mixture; a blending between oxidized and virgin binder occurs but it is very unlikely that this blending becomes complete (Mc Daniel et al., 2000). Some researchers found that this inability of the aged binder to achieve full mobilization leads to "under-asphalted" mixtures, with higher void content, reduced cracking resistance or lower resistance to water action (Al-Qadi et al., 2007; Zaumanis and Mallik, 2015).

The degree of blending between RAP, binder and new aggregates has been studied by Huang et al. (2005), who analyzed the coating obtained in the recycled mixture, subdividing it into layers, and found that the outer layers were much softer than the inner ones, putting evident that the combination of both bitumens was not uniform or complete. Others like Bowers et al. (2014) and Marsac et al. (2014), also studied the efficiency of blending by means of different techniques, such as gel permeation chromatography and infrared spectroscopy respectively. Both procedures also confirmed that blending could be incomplete.

The greater or lesser degree of blending between the RAP bitumen and the new bitumen depends, among other reasons, on the way in which the mixture is manufactured. Two manufacturing processes are clearly differentiated: RAP can be incorporated into hot mix asphalt produced in a batch plant up to a rate of approximately $20 \%$. In this case, aggregates are usually overheated in the dryer drum to get the energy required to dry and heat the RAP. For higher percentages of RAP, an adapted asphalt plant is necessary in order to preheat RAP and facilitate the blending. Two key variables are involved in the mixing process: the temperature of the mixture components and the mixing time.

Clearly the higher the temperature at which the RAP is exposed, the greater the aging that the RAP could further undergo, especially when exceeding $100^{\circ} \mathrm{C}$ (Yu et al., 2016). On the other hand, when 
RAP is incorporated at ambient temperature, increasing the mixing time favors both the total drying of RAP and the homogenous heating between the components of the mixture, resulting in a higher quality recycled mixture (Howard et al., 2009). Some studies investigated the temperature evolution and the amount of RAP binder transfer during the mixing of the overheated new aggregates and RAP; results showed that either a longer mixing time or higher overheated new aggregates is necessary when high RAP contents are to be used, as stated by Zhang et al. (2015).

For these reasons, the purpose of this study is to evaluate the mechanical properties of a mixture recycled with $20 \%$ and $40 \%$ of RAP, considering different manufacturing alternatives, simulating the effect of two variables: the temperature of the aggregates and RAP, and the mixing time.

\section{Experimental Plan and Methodology}

The aim of this study was to verify the effect of 1) mixing time and 2) temperature on bituminous mixtures, especially those containing RAP. The same mixing energy was applied through a mechanical mixer. Different combinations of temperatures were tested to evaluate their influence on aged and virgin bitumen, and their blending (Figure 1). 


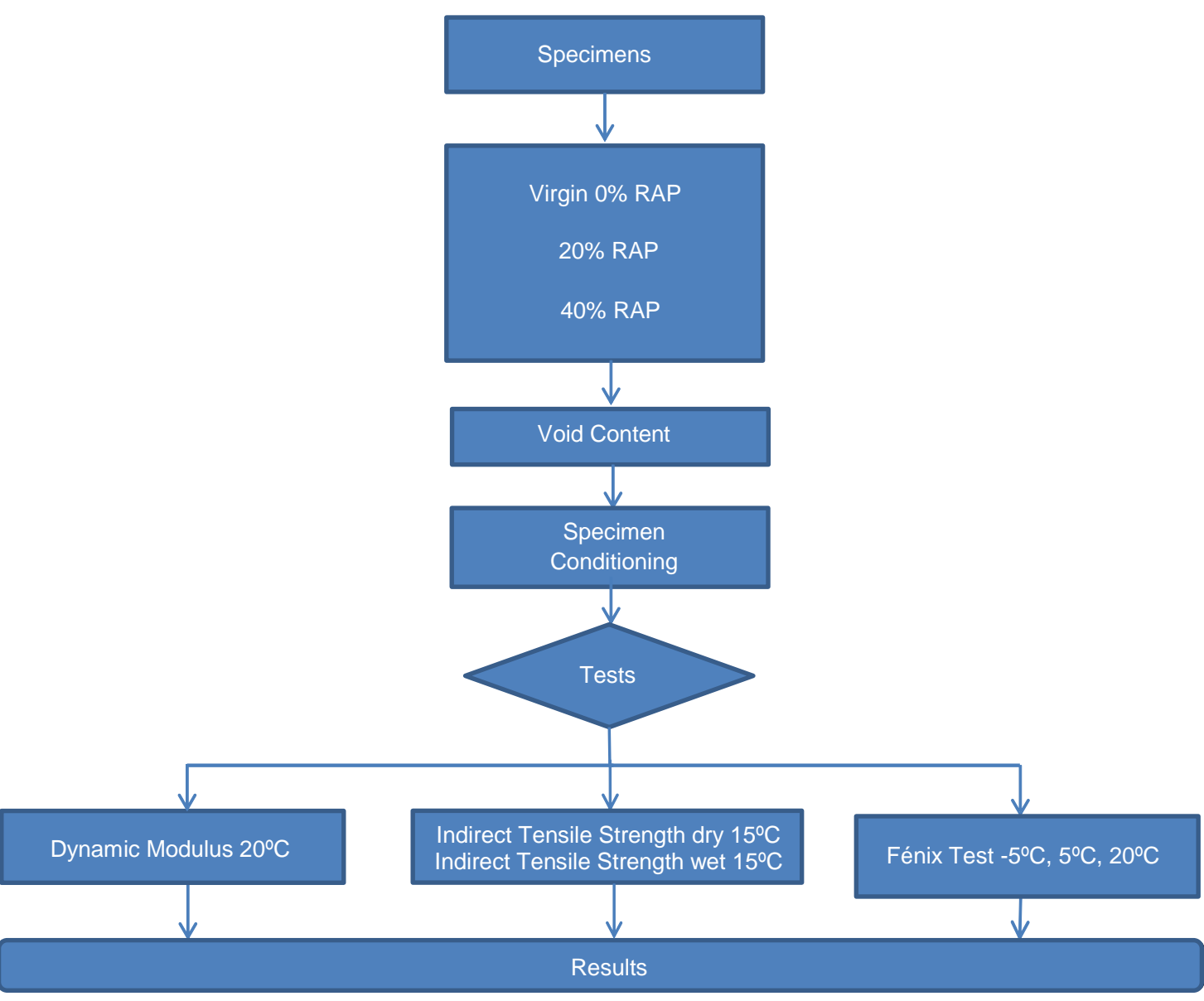

Figure 1. Experimental plan

102 The effect of these parameters was studied on mixtures containing $20 \%$ and $40 \%$ of RAP and the 103 results were compared with a reference virgin mix.

104 Void content was first calculated according to EN 12697-6 (2012) and the dynamic modulus was 105 sequentially tested (EN 12697-26, 2012). Indirect tensile strength was evaluated and sensitivity to 106 water (EN 12697-23, 2004; EN 12697-12, 2009) of the mixes was assessed. Finally, the Fénix test 107 was executed at three different temperatures. 
108 The Fénix test is commonly used to calculate the dissipated energy during the cracking formation.

109 The evaluation of this energy is an effective way of estimating cracking resistance of asphalt 110 mixtures. The half of a cylindrical specimen, $63.5 \mathrm{~mm}$ thick with a diameter of $101.6 \mathrm{~mm}$ prepared 111 by Marshall or gyratory compaction, is subjected to a tensile stress at a constant displacement 112 velocity $(1 \mathrm{~mm} / \mathrm{min})$. The test temperature is controlled. In the middle of the flat face of the 113 specimen, a $6 \mathrm{~mm}$ deep notch is made. Then, the specimen is glued to two steel plates with epoxy 114 resin. The plates are attached to a loading platen with a hinge, so that they can make a small rotation 115 (Figure 2).

116 Load and displacement data were recorded throughout the test to calculate the parameters involved 117 in the cracking process. The dissipated energy during cracking, $G_{D}$, is calculated by Equations 1 and 1182.

$$
G_{D}=\frac{W_{D}}{h l}
$$
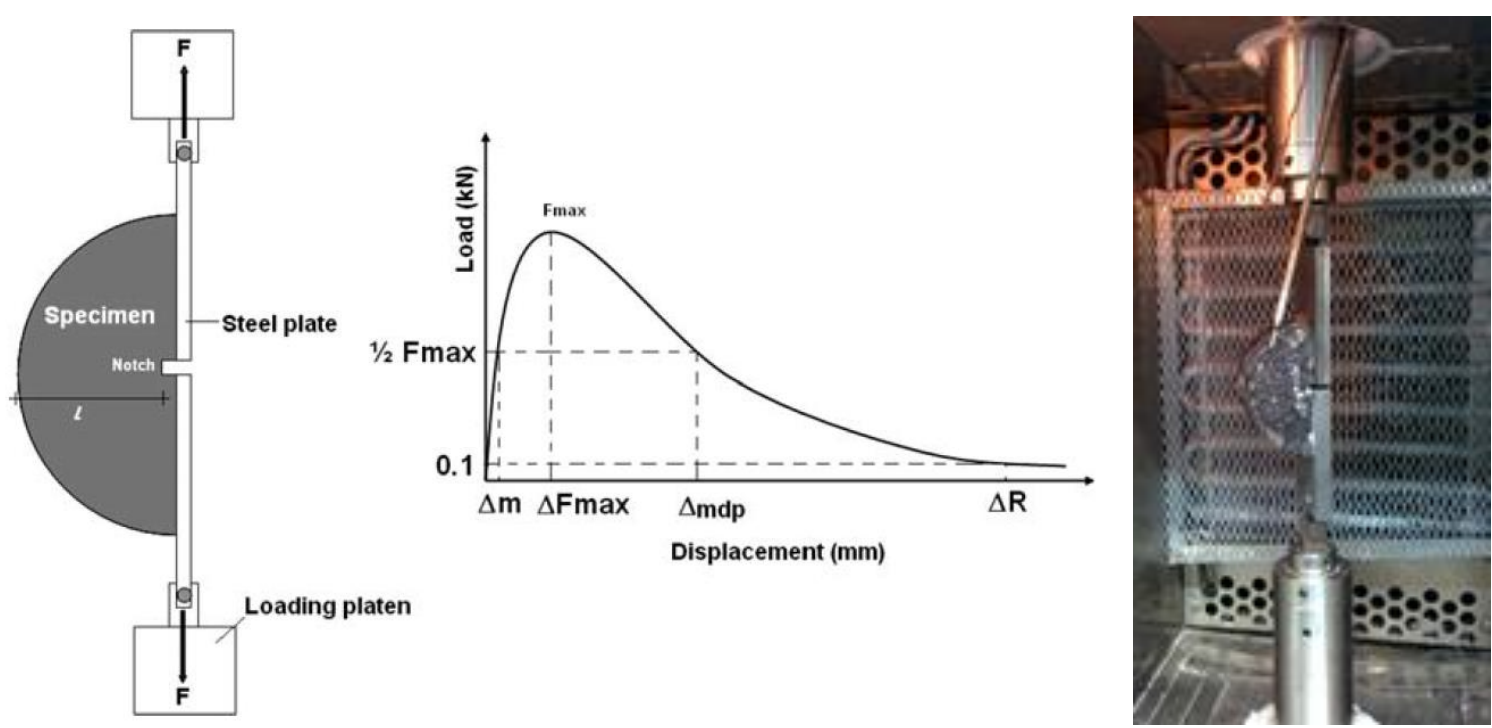

Figure 2. Typical load vs. displacement output curve and Fénix experimental set up

specimen thickness (m), and $l$ represents the initial ligament length (m).

$$
W_{D}=\int_{0}^{\Delta R} F d u
$$


123 where $F$ is the applied load $(\mathrm{kN}), u$ is the vertical actuator displacement $(\mathrm{mm})$, and $\Delta R$ is the

124 displacement at $F=0.1 \mathrm{kN}$ post peak load ( $\mathrm{mm})$ (considered as a residual value).

125 Other mechanical parameters such as peak load $\left(F_{\max }\right)$, displacement at peak load $\left(\Delta F_{\max }\right)$ and

126 displacement at $50 \%$ of post peak load $\left(\Delta_{\mathrm{mdp}}\right)$ are determined from the load-displacement curve, as

127 shown in Figure 2.

128 In previous studies (Pérez-Jiménez et al., 2010), the repeatability of the Fénix test was assessed by 129 coefficient of variation values (COV). For dissipated energy, $G_{D}$, and maximum tensile load, $F_{\max }$, 130 COV mean values of $15 \%$ and $8.5 \%$ were obtained, respectively. Based on COV values for 131 dissipated energy, the Fénix test seems to have good repeatability in comparison with other tests 132 like DC(T), and SCB tests (Wagoner et al., 2005).

\section{Materials}

134 For this study ten different mixtures were prepared (Table 1). A control mixture without RAP was 135 also analyzed. Five out of ten mixtures included $20 \%$ of RAP and were mixed varying the mixing 136 temperatures and mixing time. 


\begin{tabular}{|c|c|c|c|c|c|}
\hline & Name & $\begin{array}{c}\text { Aggregate } \\
\text { Temperature } \\
{\left[{ }^{\circ} \mathrm{C}\right]}\end{array}$ & $\begin{array}{c}\text { RAP } \\
\text { Temperature } \\
{\left[{ }^{\circ} \mathrm{C}\right]}\end{array}$ & $\begin{array}{l}\text { Mixing } \\
\text { Time } \\
{[\mathrm{min}]}\end{array}$ & $\begin{array}{c}\text { Number of } \\
\text { compaction } \\
\text { blows (Marshall } \\
\text { hammer) }\end{array}$ \\
\hline \multirow{2}{*}{$\begin{array}{c}0 \% \\
\text { RAP }\end{array}$} & \multirow{2}{*}{ Virgin } & 160 & - & 2 & 75 \\
\hline & & 160 & - & 2 & 50 \\
\hline \multirow{10}{*}{$\begin{array}{l}20 \% \\
\text { RAP }\end{array}$} & \multirow{2}{*}{ Mix 1} & 160 & 110 & 2.5 & 75 \\
\hline & & 160 & 110 & 2.5 & 50 \\
\hline & \multirow{2}{*}{ Mix 2} & 160 & 20 & 2.5 & 75 \\
\hline & & 160 & 20 & 2.5 & 50 \\
\hline & \multirow{2}{*}{ Mix 3} & 160 & 20 & 3.5 & 75 \\
\hline & & 160 & 20 & 3.5 & 50 \\
\hline & \multirow{2}{*}{ Mix 4} & 200 & 20 & 2.5 & 75 \\
\hline & & 200 & 20 & 2.5 & 50 \\
\hline & \multirow{2}{*}{ Mix 5} & 200 & 20 & 3.5 & 75 \\
\hline & & 200 & 20 & 3.5 & 50 \\
\hline \multirow{10}{*}{$\begin{array}{l}40 \% \\
\text { RAP }\end{array}$} & \multirow{2}{*}{ Mix 1} & 160 & 110 & 2.5 & 75 \\
\hline & & 160 & 110 & 2.5 & 50 \\
\hline & \multirow{2}{*}{ Mix 2} & 160 & 20 & 2.5 & 75 \\
\hline & & 160 & 20 & 2.5 & 50 \\
\hline & \multirow{2}{*}{ Mix 3} & 160 & 20 & 3.5 & 75 \\
\hline & & 160 & 20 & 3.5 & 50 \\
\hline & \multirow{2}{*}{ Mix 4} & 200 & 20 & 2.5 & 75 \\
\hline & & 200 & 20 & 2.5 & 50 \\
\hline & \multirow{2}{*}{ Mix 5} & 200 & 20 & 3.5 & 75 \\
\hline & & 200 & 20 & 3.5 & 50 \\
\hline
\end{tabular}

Table 1. Summary of the mixes

RAP was used at $110^{\circ} \mathrm{C}$ or at $20^{\circ} \mathrm{C}$, while the aggregates were heated at $160^{\circ} \mathrm{C}$ or overheated at $200^{\circ} \mathrm{C}$, with the aim of simulating the manufacturing processes explained in previous sections. Both temperatures participate to determine the final mixing temperature; thus, after mixing RAP, aggregates, bitumen and filler, the temperature of the mixture was measured with a laser thermometer. The mixing time was 2.5 minutes and 3.5 minutes.

Similarly, five mixtures with $40 \%$ of RAP were prepared. For each specific combination of mixing time and temperature, six specimens were realized with 50 blows and other six specimens with 75 blows of a Marshall impact compactor (EN 12697-30, 2013).

Mixes gradation was developed for a binder layer of the pavement; nominal maximum aggregate size was $22 \mathrm{~mm}$. The gradation of the RAP (before and after the bitumen extraction) was studied to 
identify the amount of virgin aggregates to be added to fall within the limit curves. The sieve size gradations are showed in Figure 3.

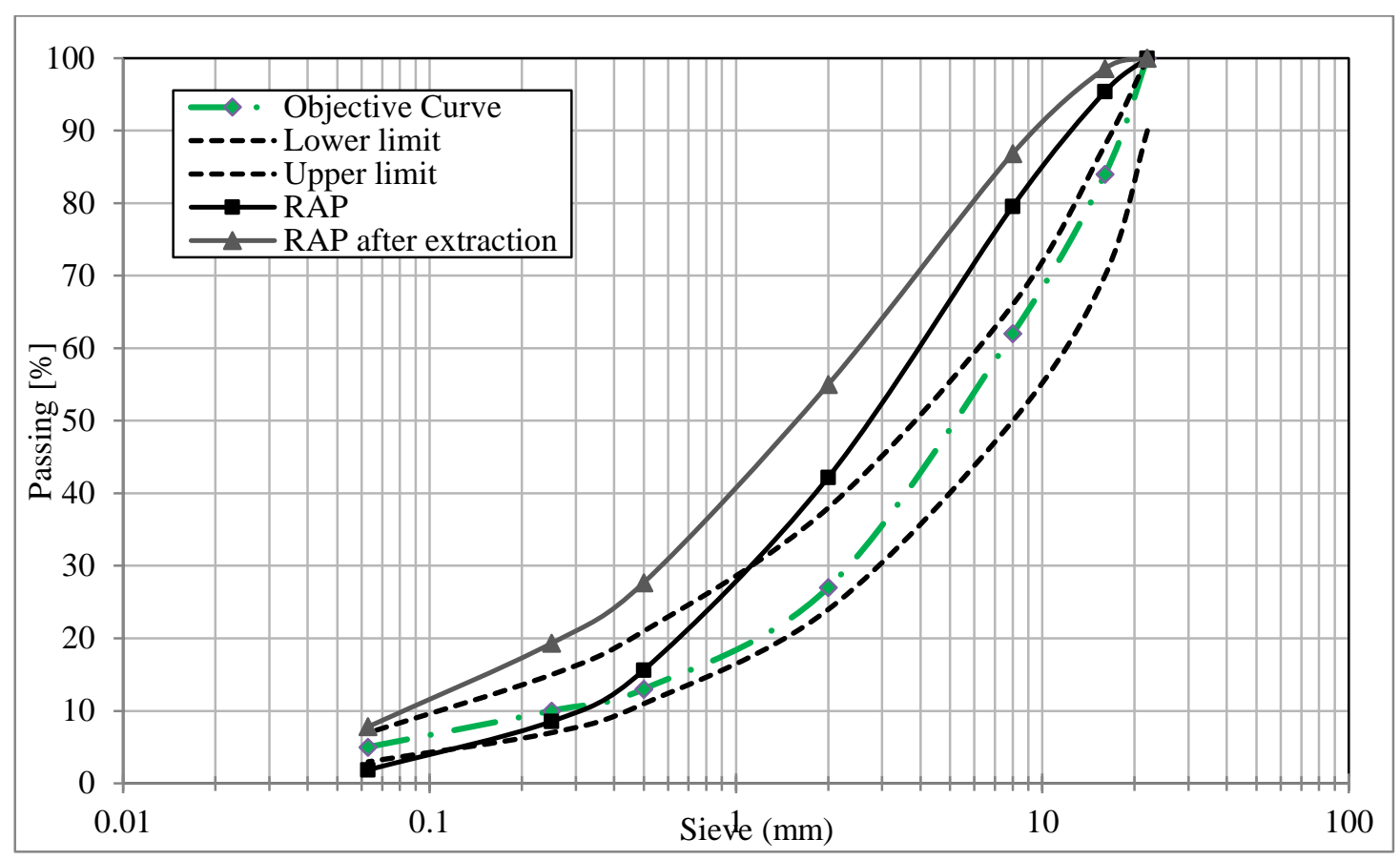

Figure 3. Gradations of materials

The virgin binder used for the specimens without RAP is $50 / 70 \mathrm{dmm}$ pen grade bitumen. Instead, 70/100 dmm pen grade bitumen was used for specimens containing RAP. It was, in fact, expected that the blending between the aged RAP bitumen and the virgin softer binder resulted in a similar performance to the $50 / 70 \mathrm{dmm}$. The amount of binder and main physical characteristics are shown in Table 2.

\begin{tabular}{|c|c|c|c|c|}
\hline & $\begin{array}{c}\text { Penetration } \\
(\text { EN 1426) } \\
(\mathrm{dmm})\end{array}$ & $\begin{array}{c}\text { Softening Point }(\mathrm{EN} \mathrm{1427)} \\
\left({ }^{\circ} \mathrm{C}\right)\end{array}$ & $\begin{array}{c}\text { Bitumen Extracted } \\
(\%)\end{array}$ & $\begin{array}{c}\text { Bitumen in the mix } \\
(\%)\end{array}$ \\
\hline $50 / 70$ pen grade & 51 & 50.9 & & 4.25 \\
\hline $70 / 100$ pen grade & 84 & 47 & 3.5 & 4.25 \\
\hline RAP binder & 7 & 87 & 4.25 \\
\hline
\end{tabular}




\section{Preliminary Results}

164 The void content was estimated for all the specimens. Figure 4 shows that increasing the amount of

165 RAP generally results in greater void content with $40 \%$ RAP mixes exhibiting up to $7.4 \%$ of voids 166 due to compaction difficulties. Longer mixing times generally decrease the content of voids because 167 the degree of blending between virgin and oxidized binders was improved and compaction was thus facilitated. Higher RAP temperatures led to a reduced viscosity in the binder and, therefore, better aggregate flow during compaction.
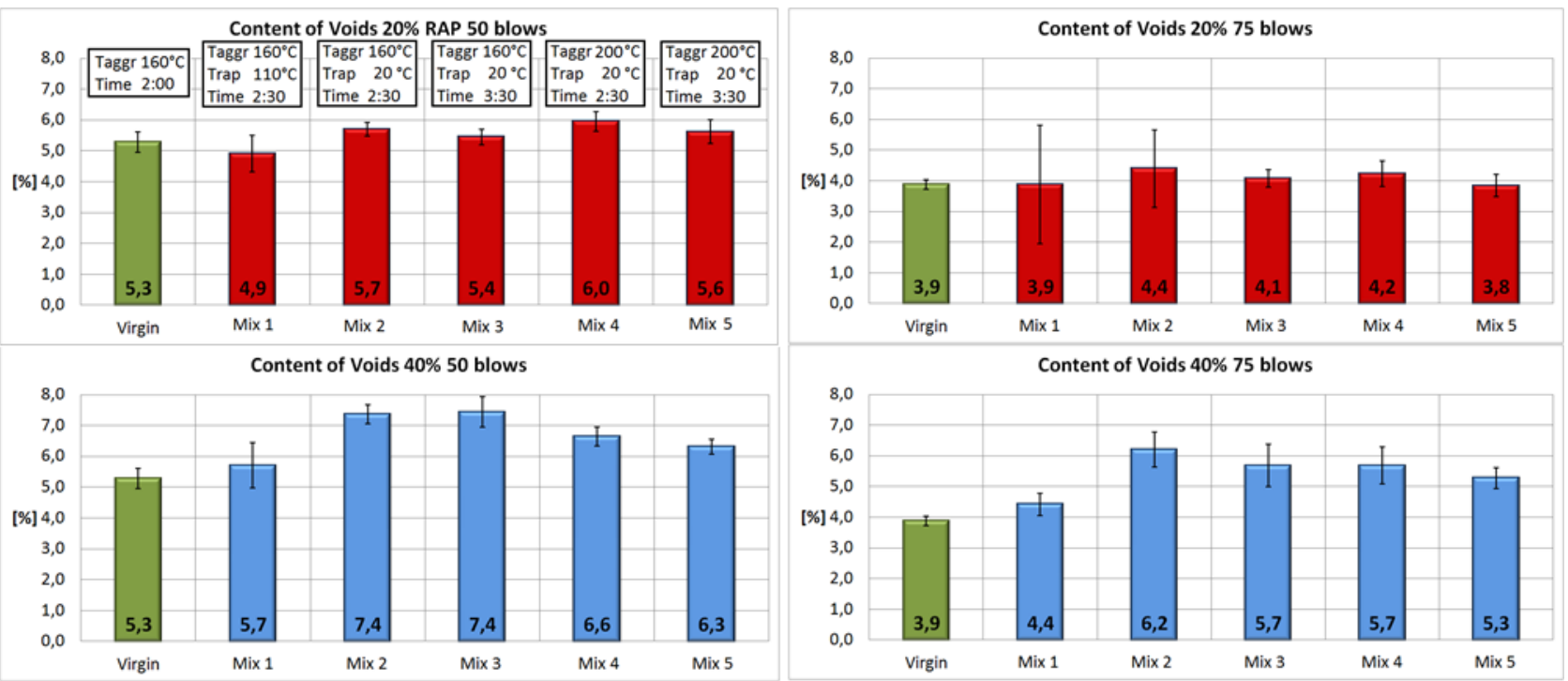

Figure 4. Void content of the mixtures

172 Dynamic modulus of 75 -blow specimens was evaluated at $20 \pm 0.5^{\circ} \mathrm{C}$. As expected, the stiffness 173 modulus was improved as the content of RAP increased.

174 If RAP is not heated (i.e.; used at $20^{\circ} \mathrm{C}$ ), the oxidized binder does not blend with the virgin binder and stiffness is reduced. Increasing mixing temperature provided an improved blending; this led to greater modulus (Figure 5). This is even more evident in specimens with 40\% RAP. Heating RAP up to $110^{\circ} \mathrm{C}$ provided a double modulus respect to the virgin mix without RAP. 

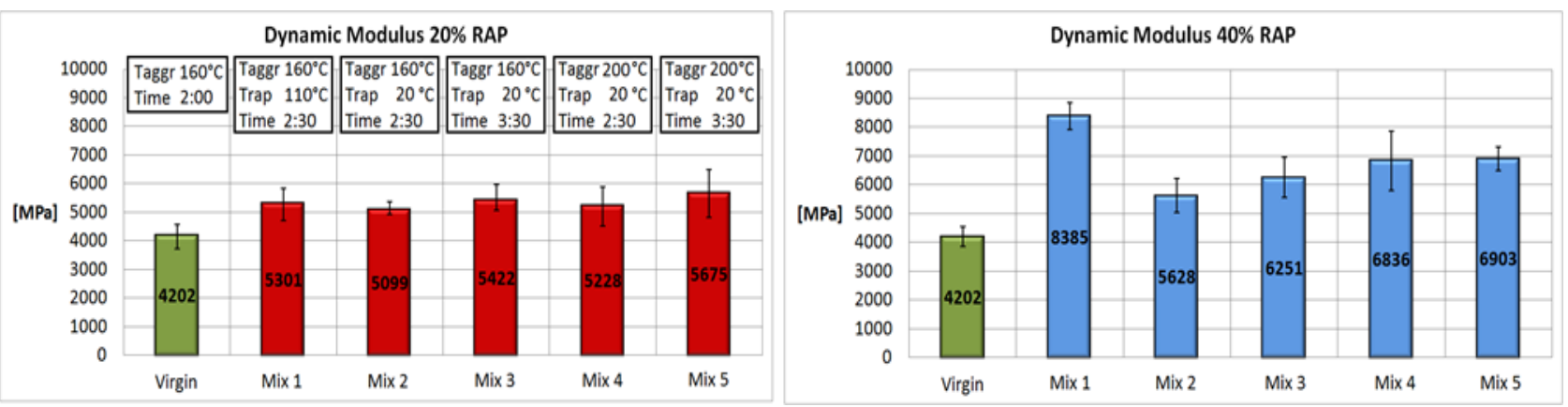

Figure 5. Dynamic Modulus of the mixtures

Increasing the mixing time provided greater stiffness due to improved degree of blending (when

RAP was heated), lower void content and greater homogeneity.

50-blow specimens were used to analyze the indirect tensile strength (Figure 6). Each mix was tested at different conditions, dry and wet, to evaluate water damage according to EN 12697-12 calculated as the ratio between the ITS $_{\text {wet }}$ and the ITS $_{\text {dry. }}$.
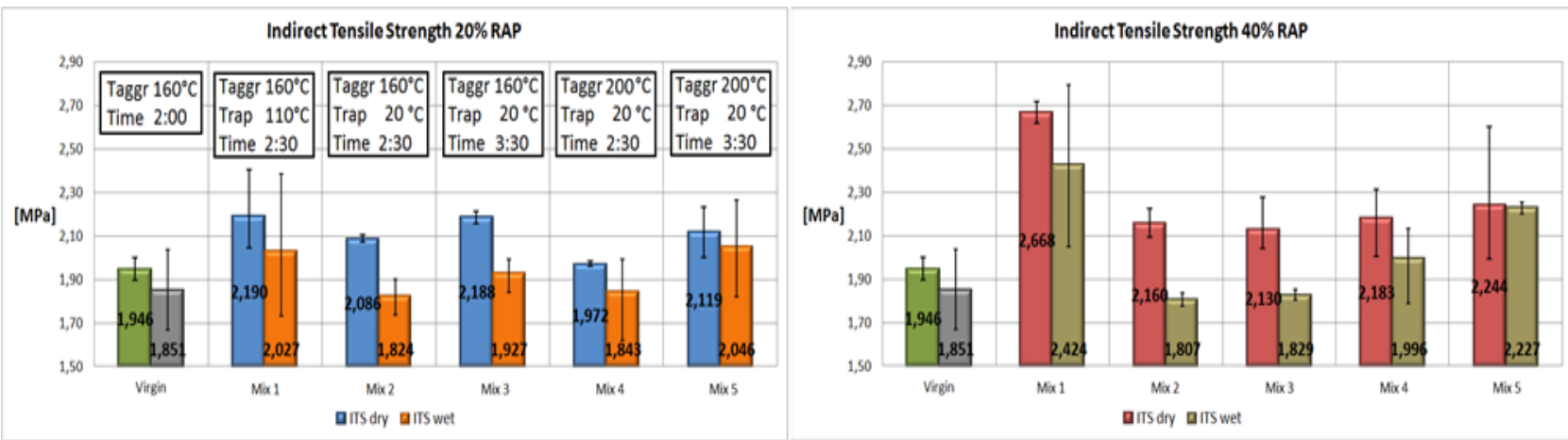

Figure 6. Indirect tensile strength of the mixtures at $15^{\circ} \mathrm{C}$

Increased water damage is shown by ITSR lower values. ITSR value ranged from $84 \%$ (Mix 2, 40\%

RAP, 2.5 minutes of mixing, $\mathrm{T}_{\mathrm{agg}}=160^{\circ} \mathrm{C}, \mathrm{T}_{\mathrm{RAP}}=20^{\circ} \mathrm{C}$ ) to $99 \%(\mathrm{Mix} 5,40 \% \mathrm{RAP}, 3.5$ minutes of mixing, $\left.\mathrm{T}_{\mathrm{agg}}=200^{\circ} \mathrm{C}, \mathrm{T}_{\mathrm{RAP}}=20^{\circ} \mathrm{C}\right)$. As demonstrated by Iwanski Chomicz-Kowalska (2012), tensile strength grows as the percentage of blended and oxidized binder increases. Generally, tensile strength is higher as the percentage of RAP in the mixes increases. The tensile strength and the water susceptibility did not seem to be greatly influenced by the mixing time. A better blending, depending on higher RAP heating temperatures, provided better mechanical performance and 
resistance to water damage (Figure 7). This could be noted in Mix 1, Mix 4 and Mix 5 where aggregates were overheated or RAP was preheated.

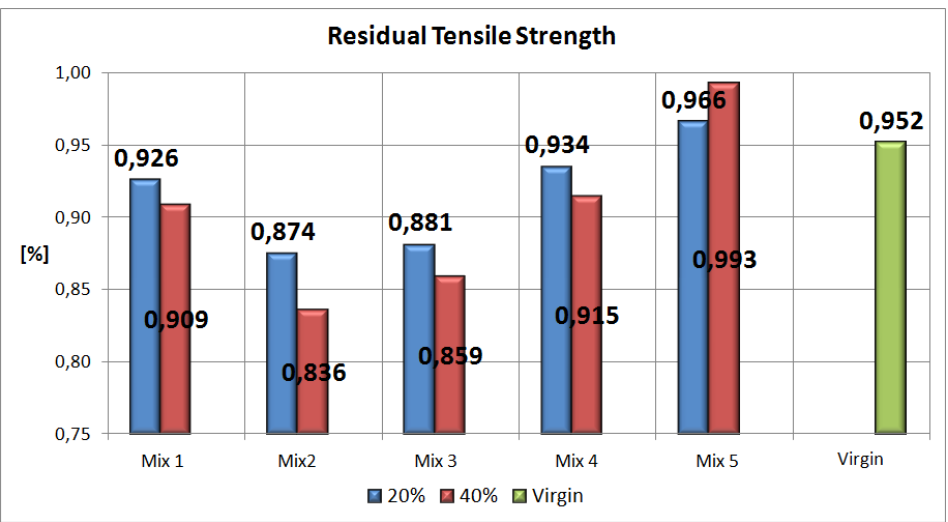

Figure 7. Indirect tensile strength ratio of the mixtures

\section{Fracture Energy}

As a matter of fact, RAP binder is commonly stiffer than the virgin binder due to aging processes. Low-temperature fracture, fracture energy and fatigue cracking should therefore be analyzed. Figure 8 shows the results of Fénix test on the reference mixtures at three different temperatures.

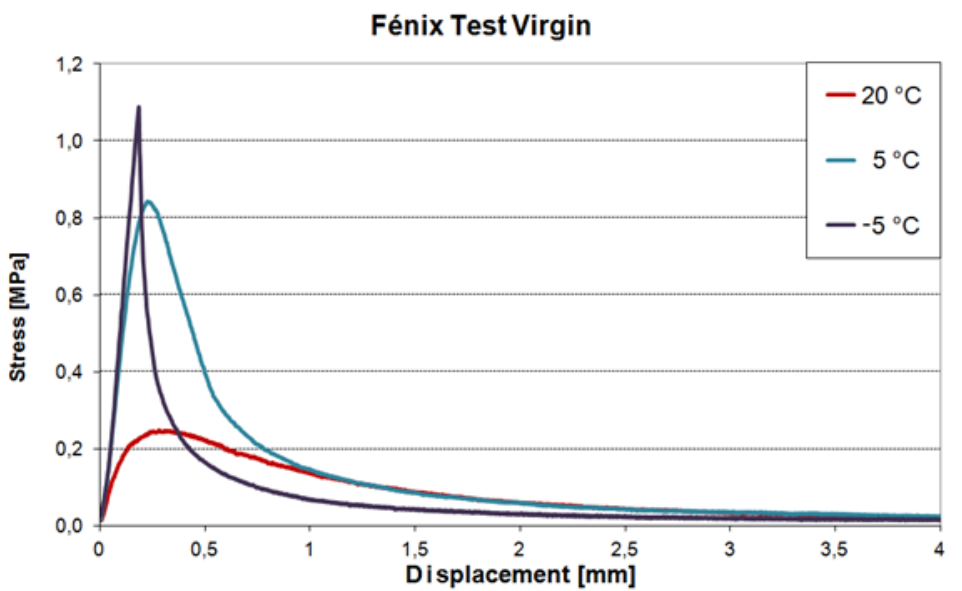

Figure 8. Fénix test at three different temperatures

Prior to fracture, the work effectuated by the load is principally stored as elastic strain energy. Upon fracture, the energy is spent in propagating the crack and irreversibly deforming the material. As the test temperature decreases the behavior of the material becomes more brittle. The slope of the elastic initial segment is increased while $\Delta_{\text {mdp }}$ (displacement at $50 \%$ post-peak load) is considerably decreased. 
The highest values of $G_{D}$ (fracture energy) were obtained at $5^{\circ} \mathrm{C}$ for $20 \%$ RAP mixes; however, adding $40 \%$ RAP resulted in a shift of the fracture energy peak at higher temperature (Figure 9). This could be related to an increased amount of less-ductile bitumen (i.e.; oxidized binder from RAP) into the mixes. The greatest fracture energy was provided by the reference virgin mix; all other mixtures broke at lower energy since the blended bitumen is weaker due to aging.

215
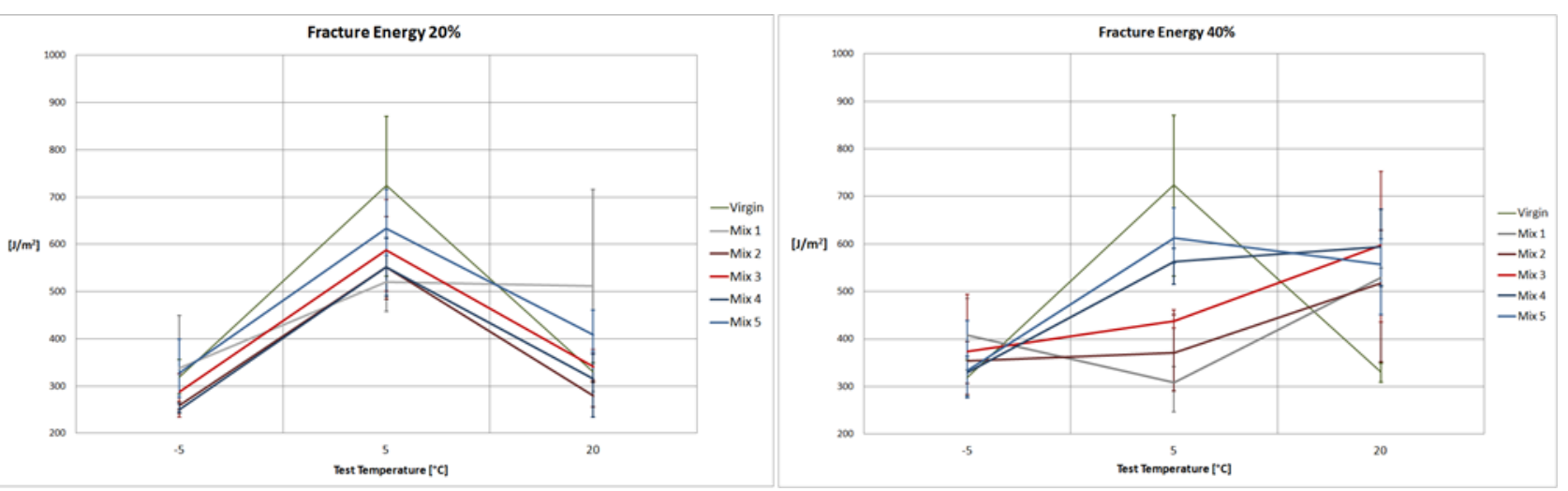

Figure 9. Fracture energy of the mixes at different temperatures

For what concerns the $\Delta_{\mathrm{mdp}}$, Figure 10 shows that at higher temperatures the behavior of the mixtures becomes more ductile. Once again the values of the displacement of the virgin mixture are the highest. It is worthwhile to notice that the virgin bitumen had a lower penetration (more ductile) than the one used in the mixtures with RAP (more fragile). This means that the aged bitumen in RAP substantially affects the good properties of the virgin one. Figure 10 also shows that a higher percentage of RAP reduces the capability of the mixtures to resist once the fracture is triggered.

Analyses about the effect of mixing time and temperature on fracture energy are provided in the following section.

\section{Influence of Mixing Time and Temperature}

The fracture energy was influenced not only by the test temperature but also by the compaction temperature (i.e.; the temperature resulting after mixing the components). The experimental results highlighted that a higher mixing temperature should bring to a higher $G_{D}$. When RAP is used at ambient temperature $\left(20^{\circ} \mathrm{C}\right)$, overheating the virgin aggregates to $200^{\circ} \mathrm{C}$ improves the resistance of the mixture. This excess in heat allows the two materials to collaborate without compromising the 
good properties of the virgin binder. In colder mixtures $\left(\mathrm{T}_{\mathrm{agg}}=160^{\circ} \mathrm{C}, \mathrm{T}_{\mathrm{RAP}}=20^{\circ} \mathrm{C}\right), \mathrm{RAP}$ behaves as a "black rock" (Al-Qadi et al., 2009) and its binder does not really participate to the final mechanical characterization. Particular attention should be paid to the mixtures with RAP heated to $110^{\circ} \mathrm{C}$; in this case the better blending considerably changed the stiffness of the mixture and led to a deterioration of the ductile properties of the virgin binder. This trend is confirmed in the mixtures with more RAP, in which the behavior of the mixtures considerably changes with the temperature.
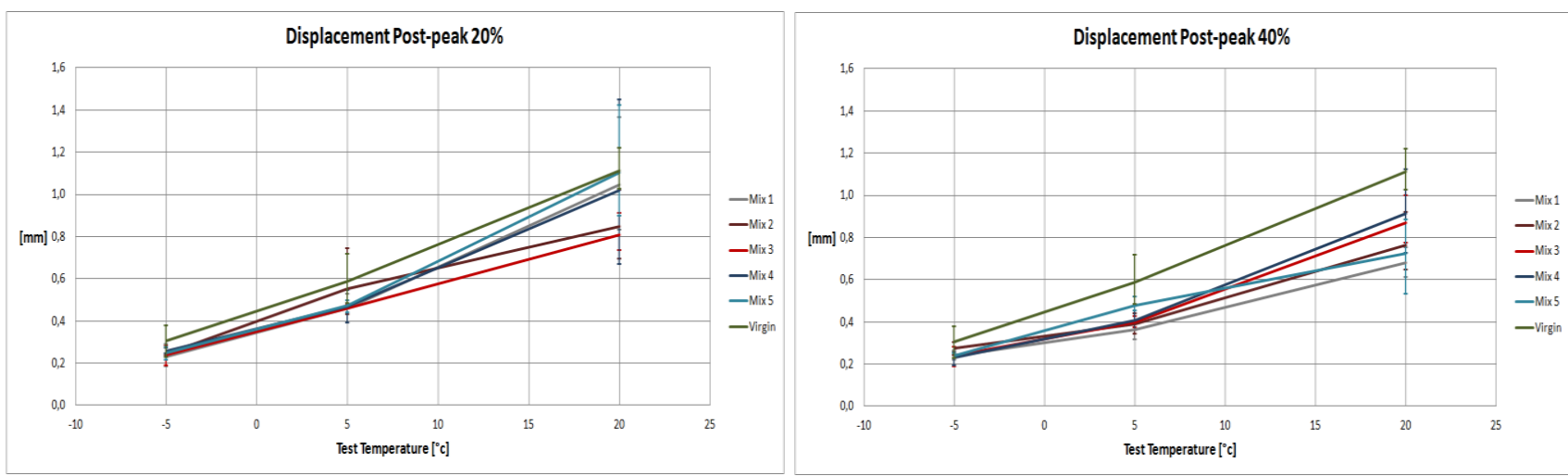

Figure 10. Displacement at 50\% post-peak load of all mixtures

A compromise between collaborating binders and high blending degree should be pursued in order to have the best mechanical performance.

In addition, increasing the mixing time has a beneficial effect on $G_{D}$, which rises, improving the fracture resistance of the material. The advantageous effect of a longer mixing time is tangible in each mix and for all RAP percentages. A well-mixed compound has a more homogeneous distribution of the aggregates and a good level of blending between the binders.

\section{Conclusions}

On the basis of the performed tests the following conclusions about the stiffness and the cracking resistance of RAP pavement mixes can be drawn.

- The void content is higher in all the mixtures that contain RAP for constant compaction energy. The aged bitumen has a greater viscosity that reduces the workability of the mixture during compaction. Results have also highlighted that an increase of mixing temperature 
implies a diminishment of voids. Increasing the mixing time makes the mix more homogenous and the same void reduction can be observed.

- Stiffness, measured by the dynamic modulus test, revealed that including RAP provides

stiffer mixes. Preheating the RAP makes the oxidized binder to collaborate with the virgin bitumen, with a consequently higher stiffness. The lowest modulus was found in the specimens with RAP at $20^{\circ} \mathrm{C}$, probably because the aged bitumen blended in a significant lower degree. An intermediate behavior was obtained by heating the aggregates to a higher temperature.

- Indirect Tensile Strength was higher for all RAP mixes, especially 40\% RAP mixes. However, lower mixing temperature and time increased the damage caused by the water (ITSR).

- Fénix tests highlighted that fracture energy is maximum at intermediate temperature $\left(5^{\circ} \mathrm{C}\right)$, although including greater RAP rates shifted the fracture energy peak toward higher temperatures. Greater mixing temperature seemed to have a positive effect on fracture energy, as long as RAP is not heated to a high temperature. Longer mixing times slightly increase fracture resistance; however, this could be caused by a reduced void content.

Finally, it was observed that bituminous mixtures containing RAP provide a stiffer behavior that could potentially turn into cracking occurring. Overheating the aggregates without preheating RAP and extending mixing time have proven to be good expedients to improve the cracking resistance of the mixtures.

\section{References}

Al-Qadi, I., Carpenter, S., Roberts, G., Ozer, H., and Aurangzeb, Q. (2009) "Investigation of working binder in Hot-Mix asphalt containing recycled asphalt pavement”. $88^{\text {th }}$ Annual Meeting Transportation Research Board.

Al-Qadi, I.; Elseifi, M. y Carpenter, S. (2007) "Reclaimed asphalt pavement: a literature review". FHWA-ICT-07-001. Illinois Center for Transportation, Chicago. 
ASTM D7313-13. (2013) Standard test method for determining fracture energy of asphaltaggregate mixtures using the disk-shaped compact tension geometry.

Bowers, B., Huang, B., Shu, X., and Miller, B. (2014). "Investigation of reclaimed asphalt pavement blending efficiency through GPC and FTIR". Construction and Building Materials 50, 517-523.

EN 12697-12 standard. (2009) Bituminous mixtures. Test methods for hot mix asphalt. Determination of the water sensitivity of bituminous specimens.

EN 12697-12 standard. (2009) Bituminous mixtures. Test methods for hot mix asphalt.

Determination of the water sensitivity of bituminous specimens.

EN 12697-23 standard. (2004) Bituminous mixtures. Test methods for hot mix asphalt. Determination of the indirect tensile strength of bituminous specimens.

EN 12697-26 standard. (2012) Bituminous mixtures. Test methods for hot mix asphalt. Stiffness. preparation by impact compactor.

EN 12697-44 standard. (2011) Bituminous mixtures. Test methods for hot mix asphalt. Crack propagation by semi-circular bending test.

EN 12697-6 standard. (2012) Bituminous mixtures. Test methods for hot mix asphalt. Determination of bulk density of bituminous specimens.

Howard, I. L., Cooley, A. L.Jr., and Doyle, J. D. (2009). "Laboratory testing and economic analysis of high RAP warm mixed asphalt” (Report Number FWHA/MS-DOT-RD-09-200). Jackson: Mississippi Department of Transportation.

Huang B.; Li, G.; Vukosavlievic, D. and Shu, X. (2005). "Laboratory investigation of mixing HMA with RAP”. Transportation Research Record 1929. 37-45.

Iwanski, M., and Chomicz-Kowalska, A. (2012) "Experimental study of water and frost resistance of foamed bitumen mixes in the cold recycling technology". Eurasphalt and Eurobitume Congress. 
Marsac, P., Piérard, N., Porot, L., Van den Bergh, W., Grenfell, J., Mouillet, V., Pouget, S., Besamusca, J., Farcas, F., Gabet, T., and Hugener, M. (2014). "Potential and limits of FTIR methods for reclaimed asphalt characterization”. Materials and Structures, 47, 1273-1286.

McDaniel, R., Soleymani, H., Anderson, M., Turner, P. and Peterson, R. (2000). "Recommended use of reclaimed asphalt pavement in the Superpave mix design method". National Cooperative Highway Research Program, Washington, D.C.

Ozer, H., Al-Qadi, I., Carpenter, S.H., Aurangzeb1, Q., Roberts, G.L., and Trepanier, J. (2009) "Evaluation of rap impact on hot-mix asphalt design and performance". Journal of the Association of Asphalt Paving Technologists, 78, 317-348.

Pérez-Jiménez, F., Botella, R., Moon, K., and Marasteanu, M. (2013). "Effect of load application rate and temperature on the fracture energy of asphalt mixtures; Fénix and semi-circular bending tests”. Construction and Building Materials, 48, 1067-1071.

Pérez-Jiménez, F., Valdés, G., Botella, R., Miró, R., and Martínez, A. (2011). “Approach to fatigue performance using fénix test for asphalt mixtures". Construction and Building Materials, 26, 372380.

Pérez-Jiménez, F., Valdés, G., Miró, R., Martínez, A., and Botella, R. (2010) "Fénix test: Development of a new test procedure for evaluating cracking resistance in bituminous mixtures". Transportation Research Record, 2181, 36-43.

Wagoner, M., Buttlar, W. and Paulino, G. (2005) "Disk-shaped compact tension test for asphalt concrete fracture". Experimental Mechanics, 45, No. 3, 270-277.

Yu, B., Gu, X., Wu, M., and Ni, F. (2016). “Application of a high percentage of reclaimed asphalt pavement in an asphalt mixture: blending process and performance investigation". Road Materials and Pavement Design, (online).

Zaumanis, M., and Mallick, R.B. (2015). "Review of very high-content reclaimed asphalt use in plant produced pavements: State of the Art". International Journal of Pavement Engineering, 16, 1, $39-55$. 
327 Zhang, K., Wen, H., and Hobbs, A. (2015) "Laboratory tests and numerical simulations of mixing

328 superheated virgin aggregate with reclaimed asphalt pavement materials". Transportation Research

329 Record, 206, 62-71. 